\title{
Fındık Kırma Yöntemleri ve Fırlatarak Kırma Hız Analizi
}

\author{
Mustafa Serkan ABDÜSSELAM ${ }^{1 *}$, Mükrimin Şevket GÜNEY²
}

\section{Öz}

Fındık kabuk kırma işlemi veya genel anlamıyla sert kabuklu yemişlerde kabuk kırma yöntemleri darbeyle kırma, sıkıştırarak basma kuvvetiyle kırma, vakum basıncıyla kırma, sert ince bıçaklarla keserek kırma, sıkıştırıp ovalayarak kırma ve fırlatıp çarptırarak kırma yöntemleri olarak sınıflandırılabilmektedir. Bu çalışmada tombul cins findığı tüp içinde kontrollü olarak hızlandırarak kırma işlemi amaçlanmıştır. Şeffaf boru/tüp içinde frekans kontrollü devir sayısı ayarlanabilen radyal fan cebri üflemesiyle tüp içinde akışı sağlanan findığın belli aralıklarda hızı ölçülmüş ve denemeler sonucunda diğer kırma yöntemleriyle rekabet edebilecek bir sistem geliştirilmiş̧ir. Geliştirilen prototip ek araştırmalarla desteklendiğinde firlatarak kırma sistemi endüstriyel üretime uygun hale gelebilecektir.

Anahtar Kelimeler: Fındık kırma, Fırlatarak Kırma, Hız Analizi.

\section{Hazelnut Cracking Methods and Throwing Breaking Speed Analysis}

\begin{abstract}
Hazelnut shell crushing methods, or in general terms, shell crushing methods in nuts can be classified as crushing by impact, crushing by compression force, breaking by vacuum pressure, breaking by cutting with hard thin blades, crushing by crushing and rubbing, and by throwing and knocking. The aim of this study is to break the chubby type hazelnut by accelerating it in a tube in a controlled manner. The speed of the hazelnut, flowing through a tube with radial fan blowing, was measured at certain intervals, and as a result of the trials, this system has been developed to compete with other crushing methods. In the form of supporting the prototype with additional research, the throwing crushing system will become suitable for industrial production.
\end{abstract}

Keywords: Hazelnut Cracking, Throwing Breaking, Speed Analysis.

\footnotetext{
${ }^{1}$ Giresun Üniversitesi, Bilgisayar ve Öğretim Teknolojileri Eğitimi Bölümü, Giresun, Türkiye, mustafa.serkan@giresun.edu.tr

${ }^{2}$ Giresun Üniversitesi, Enerji Sistemleri Mühendisliği Bölümü, Giresun, Türkiye, ms.guney@giresun.edu.tr
}

${ }^{1}$ https://orcid.org/0000-0002-3253-7932 ${ }^{2}$ https://orcid.org/0000-0002-7481-5072 


\section{Giriş}

Hızlı nüfus artışı, niteliksiz yerleşim alanlarının genişlemesi, tüketim alışkanlıkları gibi faktörler sağlıklı ve dengeli beslenme konusunu öne çıkarmaktadır. Sözü edilen yapı sorunları da birlikte getirmektedir. Özellikle birinci sınıf sulanabilir araziler bu manada oldukça değerli olmaktadır. Ordu, Giresun ve Trabzon vilayetlerinde findık tarımı uzun yıllardan bu yana yapılmaktadır. Bu şehirleri içine alan Doğu Karadeniz Bölgesi coğrafi yapısı bakımından engebeli ve yüksek engebeli arazilerden oluşmaktadır, dolayısıyla birinci sınıf sulanabilir arazi değildir. Bu tarz arazi yapısında tarımsal ürerim olanakları fındık, çay ve kivi gibi ürünlerle sınırlı kalmaktadır. $\mathrm{Bu}$ bölgede sürdürülebilir fındık tarımının sağlanması önem arz etmektedir (Güner ve Güney, 2018).

Fındık işleme süreçleri ise genellikle büyük ölçekli işletmeler yoluyla yapılmaktadır. İşletme kapasiteleri oldukça yüksektir. Sektörde faaliyet gösteren firmalar genellikle tekel oluşturan alıcılar vasıtasıyla yönlendirilmektedir. Bu firmalar son ürüne şekil vermektedirler ve ara işlemlerdeki etkinlik, işletme maliyetlerindeki azatlımlar ve ürün zayiatı gibi faktörler derinlemesine incelenmemekte, sistem üzerinde nitelikli dokunumlar ve araştırmalar eksik kalabilmektedir. Bu çalışmada, fındık kırma süreçleri incelenerek özellikle fırlatarak kırma yöntemleri tanıtılmış ve süreç esnasında oluşan hava hızları deneysel olarak belirlenerek öngörüler ortaya konulmuştur.

Kabuklu yemişleri, kabuk sertliklerine göre yumuşak, orta ve sert kabuklu olarak adlandırabilmek mümkündür. Fındık, Ceviz, Badem, Antep Fıstığı gibi sert kabuklu yemişler bozulmadan uzun süre saklanabilmektedir. Bu nedenle ve besin değerleri bakımından insanoğlunun ve diğer canlıların evrimsel süreçte milyonlarca yıldır bol miktarda tükettiği bir besin grubu olmaktadır. Sert kabuklar kırılırken içindeki yemişi ezip un ufak etmeyecek şiddette bir kuvvet ve /veya yöntem uygulamak gerekmektedir (Kınıkoglu, 2015). Kabuklu yemiş kırma sistemleri genel itibarıyla manuel ve dış güç kullanımlı sistemler olarak sınıflandırılabilmektedir (Hussain ve ark., 2018). Endüstriyel findık kırma sistemi ilave ön ve son işlemlerde beraberinde gerektirmektedir. Bunlar sırasıyla kalibrasyon, kırma, kabuk ayırma, iç fındık kalibrasyonu ve iç findığın seçilmesi aşamalarından oluşmaktadır (Özdemir ve Özilgen, 1997). Fındık kırma olarak adlandırılan, fındığın iç kısmının kabuğundan ayrılması süreci işleme maliyetlerini ve ürün kalitesini yakından etkilemektedir (Güner, Dursun ve Dursun, 2003). Kırma esnasında fındık içinden parça kopması "vurgun" olarak adlandırılmaktadır. Bu ise findığın lipid temelli zengin besin içeriğinde bozulmaya neden olmaktadır (Ghirardello ve ark., 2013). Ayrıca vurgun sonucunda raf ömrü ve findık yağı gibi elde edilecek diğer nihai ürün kalitesi de olumsuz etkilenmektedir. (Arjun, Girish, Nagaraju ve Sridhar, 2016; Delprete ve Sesana, 2014).

Pratik uygulamada var olan sistemleri vurarak darbeyle kırma, sıkıştırarak basma kuvvetiyle kırma, vakum basıncıyla kırma, sert ince bıçaklarla keserek kırma, sıkıştırıp ovalayarak kırma ve 
fırlatıp çarptırarak kırma olarak ayrıştırılabilmektedir. Bunlar arasında sıkıştırıp ovalayarak kırma yaygın uygulanan yöntemdir ve endüstriyel kullanımı uzun yıllardır mevcuttur. Ancak ölçeği bakımından büyük ölçekli işletmelere uygundur, bilindiği gibi büyük ölçekte işletmelerin girdi maliyetleri daha yüksektir. $\mathrm{Bu}$ ise rekabetçi fiyat oluşumuna olumsuz etki etmektedir. Kısaca bu sistem küçük ve orta işletmelerin rekabetine izin vermemektedir. Bu çalışmada yapısal olarak çok karmaşık olmayan, diğer ön ve son işlemlere daha az gereksinim duyan, işletme maliyetleri bakımından da avantaj oluşturabileceği öngörülen firlatarak kırma sistemleri üzerinde durulmaktadır. $\mathrm{Bu}$ sistemlerde kırma çenesi veya plakasına ulaşmadan hemen önceki fırlatma hızları belirlenmektedir. Bu amaçla gerekli deney düzenekleri oluşturulmuştur.

\section{Materyal ve Metot}

Fırlatarak kırma cebri fan üflemesiyle bir boru veya tüp içinde kontrollü olarak hızlandırılan ürünün boru çıkışında sert bir yüzeye çarptırılması ile sağlanmaktadır. Bu sert yüzey bir metal plaka olabilmektedir. Çarpan ürünün zarar görmeden biriktirilmesi sağlanmalıdır.

$\mathrm{Bu}$ çalışmada kullanılan ürünler tombul cins fındıklardır. Yetiştikleri iklim bakımından sahil şeridine ait denizden yüksekliği 110-160 metre olan Ordu ili Öceli köyünden temin edilmiştir. Kullanılan ürünlerin çap büyüklükleri 11-13 mm olarak tespit edilmiştir. Furlatma ve ürün hızlandırma işlemleri yüksek basınçlı radyal fan vasıtasıyla uygulanmıştır.

\subsection{Deney Düzeneği}

Elektrik motoruna direkt akuple 3 fazlı $2 \mathrm{~kW}$ motor güçlü radyal fan tercih edilmiştir. Bu güçteki bir fanı tek fazlı şebekeden güç alarak üç fazlı tahrik yapabilen, kademesiz biçimde üfleme hız ayarı yapabilen invertör kullanılmıştır. Fan çıkışında ürün yüklemeyi mümkün kılacak biçimde tasarımlanan yükleme ağZı oluşturulmuştur. Yüklenen ürünün hızlanmasını temine yönelik $30 \mathrm{~mm}$ çapında ve 2 metre uzunluğunda şeffaf üfleme borusu mevcuttur. Boru çıkışında çarpma çenesi olarak kullanılan bir plaka yerleştirilmiştir. Boru boyunca fandan itibaren 90, 140 ve $190 \mathrm{~cm}$ mesafede olacak şekilde ürünün şeffaf borular içinden geçişini algılayan sensörler yerleştirilmiştir. Ürünün bu sensörlerden geçiş zamanları kullanarak ortalama hızlar belirlenmektedir. Bu ortalama hızlardan yola çıkarak çarpma anındaki ürün hızı belirlenebilmektedir. Deney düzeneği Şekil 1 de verilmektedir. 


\subsection{Deney Presedürü}

Fırlatma işlemi için öncelikle radyal fan invertör üzerinden çalıştırılmıştır. Belirli bir hava hızına ulaşıldığında ürünler yükleme nozulundan içeriye gönderilmiştir. Öncelikle $30 \mathrm{~mm}$ çapındaki boru içinde ürünlerin sürüklenme hızlarının aşılması hedeflenmiştir. Bu sağlandıktan sonra fan hızı aşama aşama artırılarak ve her hızda bir ürün gönderilerek firlatma işlemi gerçekleştirilmiştir. Hızlar artarken ve kayıt edilirken firlatma sonucunda kabuk kırılmanın başladığı invertör frekansları belirlenmiştir. Kırılma başlamasına rağmen ürünler verilirken hızlar bir miktar daha artırılarak testler sürdürülmüştür. Bu esnada fındık içlerinde vurgun, yarılmalar ve parçalanmaların başladığı hızlar belirlenmiştir. $\mathrm{Bu}$ belirlenen hızlar arasında fırlatarak kırılmanın optimum olacağı değerler ortaya çıkarılmıştır.

\subsection{Modelleme}

Sistemin elektronik tasarımı donanım ve yazılım olmak üzere iki bölümde incelenmektedir. Donanım mikrodenetleyici, hareket algılama sensörleri ve LCD ekranı kullanılarak oluşturulmuştur. Yazılım bölümünde ise bu donanımlar aracılığgyla üfleme borusunda hareket eden nesnenin algılanarak tüpten nesnenin giriş ve çıkış hızlarının hesaplanması gerçekleştirilmektedir.

Araştırmada geliştirilen sistemin öncelikle mekanik bölümü tamamlanmış, ardından hazırlanan mekanik parçaların üzerine mikrodenetleyici ve sensörler yerleştirilmiştir. Son aşamada ise amaçlanan fonksiyonları gerçekleştirmek amacıyla sistem programlanmış ve sınanmıştır. Sistemin genel yapısı Şekil 1'de görselleştirilmiştir.

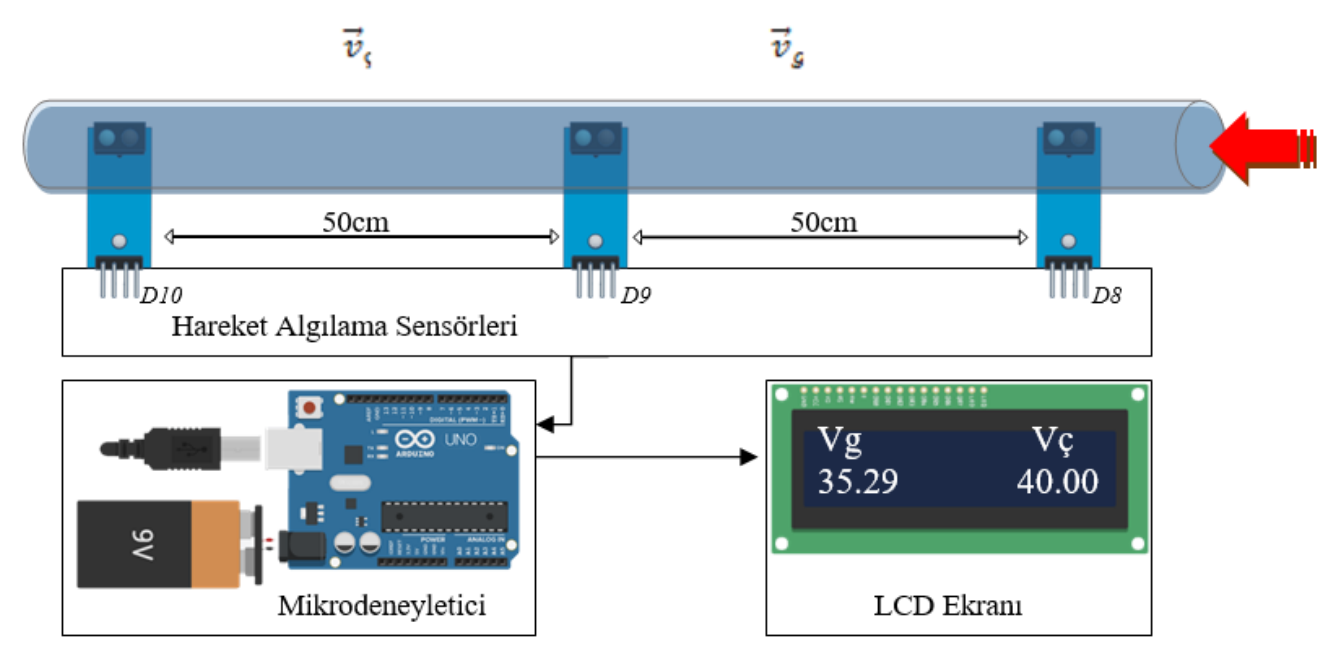

Şekil 1. Sistemin Genel Diyagramı. 
Sistemin genel diyagramı incelendiğinde üfleme borusundan bir nesne girişi gerçekleştiğinde hareket algılama sensörleri tetiklenmektedir. Sensörlerin tetiklenmeleri arasındaki süre farklılıkları mikroişlemci tarafından hesaplanmaktadır. Her iki sensör arasında sabit tutulan uzaklık $(50 \mathrm{~cm})$ ile süre farklılıkları, ortalama hız formülü (1) kullanılarak hesaplanmış ve nesnenin giriş çıkış hız ortalamaları LCD ekranında yazdırılmıştır.

$$
\vec{v}_{\text {ort }}=\frac{\sum \Delta \vec{x}}{\sum t}
$$

Sistem kapsamında kullanılan Arduino Uno mikrodenetleyici ATmega328P işlemcisi temelli bir karttır. Bu kart hem dijital hem de analog giriş/çıkış pinleri barındırmaktadır. Giriş gerilimi 7$12 \mathrm{~V}$, çalışma gerilimi ise 5,5V'dir. USB kablosu ile programlanabilen bu kart istendiğinde AC-DC adaptörü ya da 9V pille çalıştırılabilmektedir. Hareket algılama kısmında mesafeyi ve hareketi algılayan android uyumlu kızılötesi A1H8X modülü kullanılmıştır. Bu modül, kızılötesi LED ve foto dirençten oluşan TCRT5000 k1zılötesi yansıma sensörü, LM393 komparatör entegresi ve bir potansiyometreden oluşmaktadır. Bu modül üzerinde kızılötesi alıcı ve verici bulundurmaktadır. Modül, karşı yüzeye kızılötesi 1şık yayarak geri yansıyan 1şın parlaklığını foto direnç üzerinden ölçmektedir. Ölçümler dijital ve analog değerler olarak alınabilmektedir. Dijital çıkış kullanımı durumunda elde edilen değerler 0 ve 1 'dir. Modül üzerinde bulunan potansiyometre ile kalibrasyon yapılabilmekte ve tetikleme mesafesi $0,2 \mathrm{~mm}$ ile $15 \mathrm{~mm}$ arasında ayarlanabilmektedir.

Geliştirilen sistemin yazılımında üç hareket algılama sensöründen elde edilen veriler değerlendirilmektedir. Her üç sensör birbirinden $50 \mathrm{~cm}$ uzaklıkta sıralı bir şekilde şeffaf bir yapıda olan üfleme tüpüne dik bir açı ile yerleştirilmiştir. Böylece üfleme tüpünün içinden geçecek olan nesnenin hareketlerinin tespiti için en iyi konum belirlenmiş olmaktadır. Deneyde her bir tetikleme anı bir değişkene atanarak nesnenin tüp girişinde ve çıkışındaki ortalama süreleri elde edilmiştir. Yazılımda kurgulanan algoritmanın akış şeması Şekil 2'de verilmiştir. 


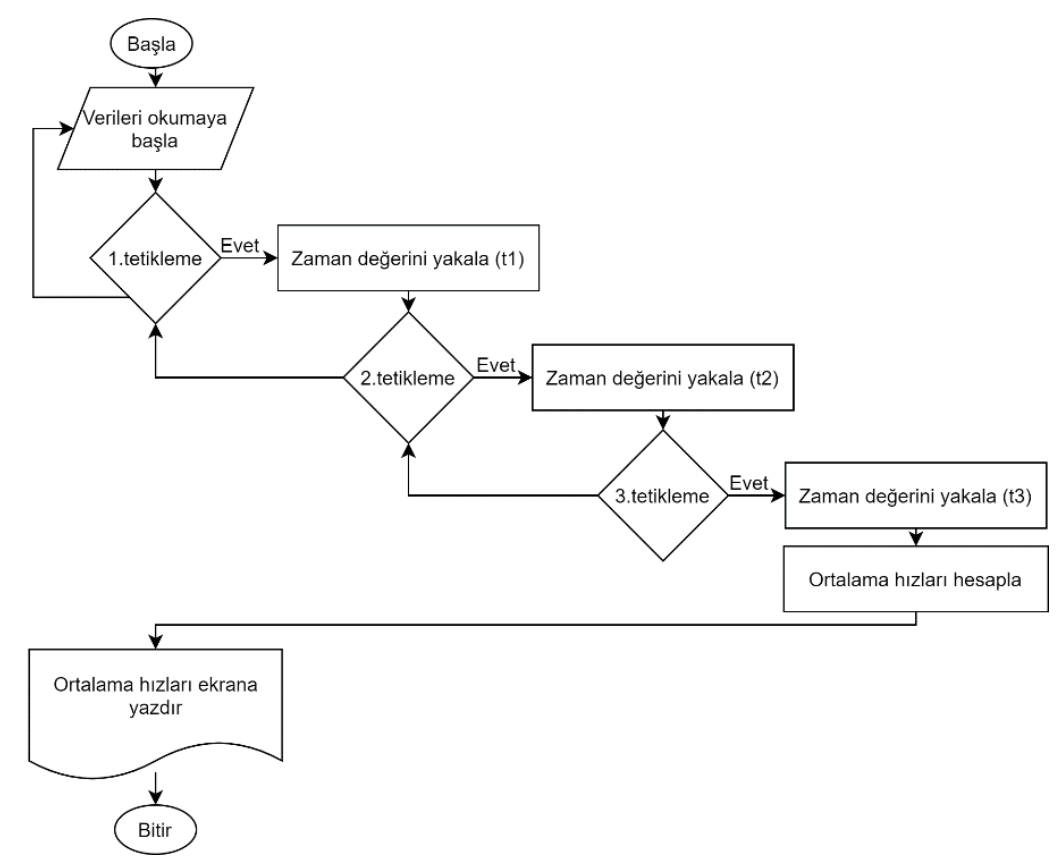

Şekil 2. Algoritmanın akış şeması.

$\mathrm{Bu}$ kapsamda gerçekleştirilen sistem ile farklı hava hızlarında denemeler yapılmış ve kabuğunun kırılması için fırlatılan fındığın son durumu kayıt altına alınmıştır. Şekil 3 'te geliştirilen sistemi görseli sunulmuştur.

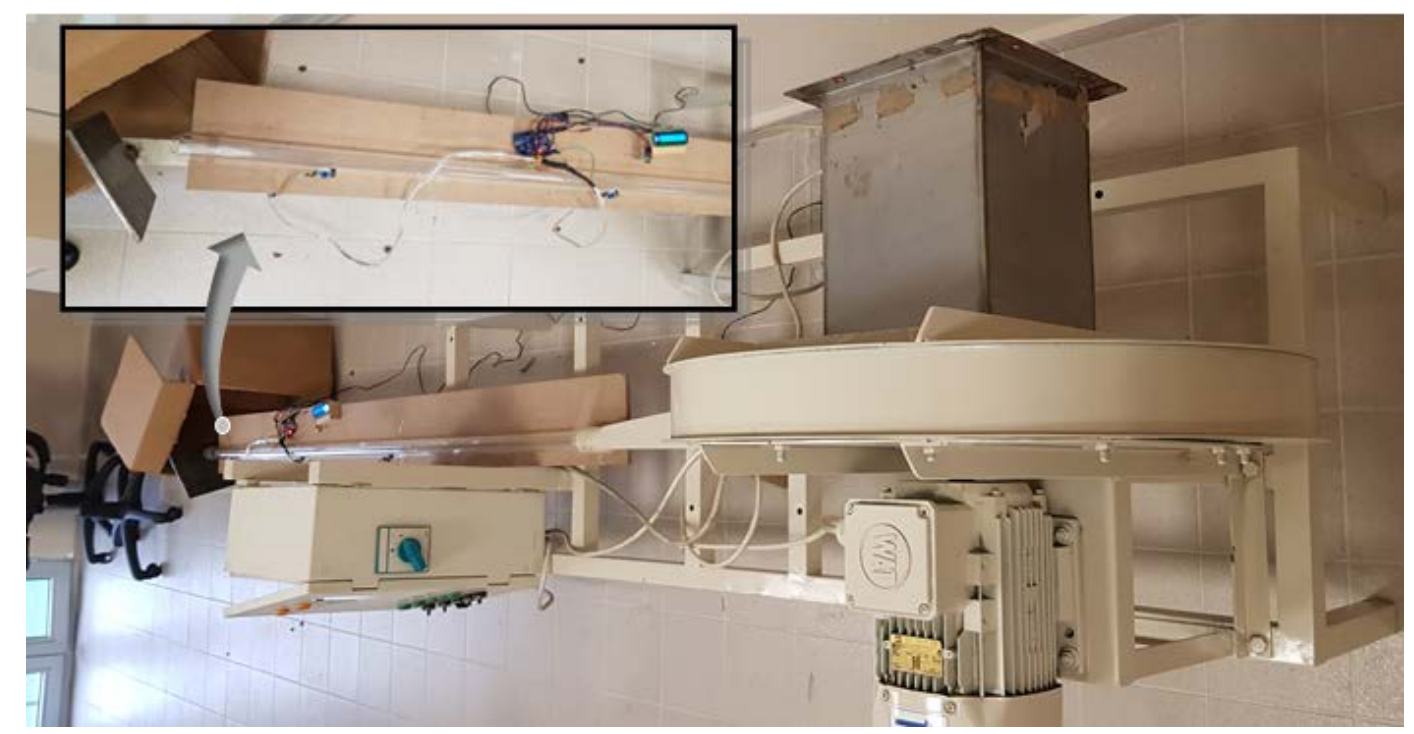

Şekil 3. Geliştirilen sistemin görseli.

\section{Bulgular ve Tartışma}

Çalışma Tombul findıklar incelenerek yürütülmüştür. Fırlatarak kırma yönteminde belirlenen hızlar bu cins fındıklar için belirlenmiştir. Fındıklar türleri bakımından kabuk kalınlıları ve sertliklerinde farklılıklar göstermektedir. Ayrıca aynı tür fındıklar arasında kabuk nitelikleri (kalınlık, 
sertlik vb. ) bakımından da farklılıklar gözlenmektedir. Diğer yandan kırma amaçlı kullanılan plaka veya kırıcı levhanın malzemesi, sertliği, yüzey pürüzlülüğü, çarpma açısı vb. faktörlerde kırma sürecindeki niteliği etkilemektedir. Burada hedeflenen diğer kırma sistemleriyle rekabet edebilir özellikte, küçük ve orta büyüklükte işletmelere de uygun bir sistem oluşturmaya yönelik başlangıç çalışmalarının ortaya konulmasıdır. Böyle bir sistemden beklenenler olarak; üründeki vurgun tabir edilen zararların azaltılması, kırma sonu kabuk açma oranlarının yükselmesi, enerji sarfiyatı bakımından diğer sistemlere göre avantajlı durum tesisi gibi özellikler sıralanabilmektedir. $\mathrm{Bu}$ çalışmada, efektif bir kabuk kırma ve kabuktan ayrılma süreci için gerekli ortalama çarpma hızı 40 $\mathrm{m} / \mathrm{s}$ olarak belirlenmiştir. Ayrıca ürünün sürüklendiği hava huzmesinin hareketinin çok kısıtlanmadan uygun büyüklükte bir boru içinde olması gerektiği anlaşılmaktadır. Diğer yandan ürünün sürüklenerek hılanmasına yetecek uzunlukta bir boru veya akış kanalı düzeneği oluşturulması gerektiği öne çıkmaktadır.

$\mathrm{Bu}$ denemelerin sonuçları üç farklı durum altında sınıflandırılabilir. Birinci durum, fırlatılan fındığın kabuğunun kırılmaması, ikinci durum fındık içine zarar vermeden kabuğundan ayrılması, son durum ise findık kabuğu kırılsa da iç fındığa zarar gelmesidir. Ürünün bu üç durumdan hangisinde olduğu hava hızına bağlıdır.. Hesaplamalar sonucunda araştırma kapsamında amaçlanan ikinci durumun oluşması için üfleme borusunun çıkış hızının ortalama 40m/s olması gerektiği tespit edilmiştir. Bu durumlar Tablo 1'de gösterilmiştir.

Tablo 1. Süreç kapsamında findık kabuğu ve içi durumları.

\begin{tabular}{cccc}
\hline Durum & Çıkış Ortalama Hız & Fındık Kabuğu & Fındık İçi \\
\hline 1 & $<40 \mathrm{~m} / \mathrm{s}$ & Zarar Gördü & Zarar Gördü \\
2 & $\sim 40 \mathrm{~m} / \mathrm{s}$ & Zarar Görmedi & Zarar Görmedi \\
3 & $>40 \mathrm{~m} / \mathrm{s}$ & Zarar Görmedi & Zarar Gördü \\
\hline
\end{tabular}

\section{Sonuçlar ve Öneriler}

Kırma sistemleri sınıflandırılmak istendiğinde darbeyle kırma, sıkıştırarak basma kuvvetiyle kırma, vakum basıncıyla kırma, sert ince bıçaklarla keserek kırma, sıkıştırıp ovalayarak kırma ve fırlatıp çarptırarak kırma yöntemleri olarak ayrıştırılabilmektedir. Bunlar arasında sıkıştırıp ovalayarak kırma yaygın uygulanan yöntemdir ve endüstriyel kullanımı uzun yıllardır mevcuttur. Bu sistemler genellikle kırma değirmenleri olarak adlandırılmaktadır ve kırıcı taş olarak doğal taş malzemeler tercih edilmektedir. Ancak bu sistemlerin kırma kapasiteleri oldukça yüksektir ve kırıcı taş büyüklüğüne göre 1-2 ton/saat kırma kapasiteleri söz konusudur. Kullanılan taş çapları genellikle $1.200 \mathrm{~mm}$ değerindedir. Ağır ve hantal sistemlerdir. Ayrıca verilen kapasite değerlerinden anlaşılacağı üzere küçük ve orta büyüklükteki işletmelere uygun değillerdir. Bu sistemlerde mutlaka 
değirmene girmeden önce ürüne çap büyüklük sıralaması yapılması gerekmektedir. Bu sistemlerde geniş hacim işgal eden hantal sistemlerdir. Fırlatarak kırma sistemlerinde ön büyüklük sıralaması yapma gereksinimi yoktur. Sistemin geliştirilmesine yönelik olarak bazı tamamlayıcı çalışmalara ihtiyaç olduğu belirlenmiştir. Öncelikle farklı büyüklükteki ürünün aynı çaptaki boru veya akış kanalı içinde hızlanma farklılaşmasının izlenmesi, daha sonra farklı cins fındıkların ideal çarpma hızlarının belirlenmesi gerekmektedir. Ayrıca çarpma plakası malzeme ve sertliğinin değişimi ile ideal çarpma hızlarının belirlenmesi, çarpma plakası pozisyonlanma açısının (kısaca çarpma açısı olarak adlandırılabilir) belirlenmesi ve çarpma plakası yüzey pürüzlülüğün ideal çarpma hızına etkisi de belirlenmelidir. Yapılmış olan bu temel çalışma yukarıda sıralanan ek araştırmalarla desteklendiğinde fırlatarak kırma sistemi endüstriyel kullanıma uygun ürün haline getirebilecek, küçük ve orta büyüklükteki işletmeler için yeni ufuklar açabilecektir.

\section{Teșekkür}

Çalışmanın altyapısına vermiş olduğu desteklerden dolayı Giresun Üniversitesi Bilimsel Araştırma Projeleri Koordinasyon Birimine, çalışmaya sağlamış olduğu bilimsel katkılarından dolayı Dr.Öğr.Üyesi Faruk GÜNER'e teşekkür ederiz.

\section{Kaynaklar}

Arjun, S., Girish, G., Nagaraju, V. D., \& Sridhar, B. S. 2017. Physico-fracture characteristics of Makhana (Euryale ferox) seeds. International Journal of Food Properties, 20(sup2), 1204-1209. doi. 10.1080/10942912.2016.1214843

Delprete, C., \& Sesana, R. 2014. Mechanical characterization of kernel and shell of hazelnuts: Proposal of an experimental procedure. Journal of Food Engineering, 124, 28-34. doi: 10.1016/j.jfoodeng.2013.09.027

Ghirardello, D., Contessa, C., Valentini, N., Zeppa, G., Rolle, L., Gerbi, V., \& Botta, R. 2013. Effect of storage conditions on chemical and physical characteristics of hazelnut (Corylus avellana L.). Postharvest Biology and Technology, 81, 37-43. doi: 10.1016/j.postharvbio.2013.02.014

Güner, F., \& Güney, M. Ş. 2018. Situation analyses of hazelnut sector, the necessity and classification of harvesting machines. Turkish Journal of Agriculture-Food Science and Technology, 6(9), 1141-1147. doi: 10.24925/turjaf.v6i9.1141-1147.1926

Güner, M., Dursun, E., \& Dursun, I. G. 2003. Mechanical behaviour of hazelnut under compression loading. Biosystems Engineering, 85(4), 485-491. doi: 10.1016/S1537-5110(03)00089-8

Hussain, S. Z., Ammatullah, B., Kanojia, V., Reshi, M., Naseer, B., \& Naik, H. R. 2018. Design and development of technology for walnut cracking. Journal of Food Science and Technology, 55(12), 49734983. doi: 10.1007/s13197-018-3435-0

Kınıkoglu M. 2015. Kabuklu Kuruyemişler. Retrieved from: http://www.doktormurat.net/makale/1272/kabuklu-kuruyemisler

Özdemir, M., \& Özilgen, M. 1997. Comparison of the quality of hazelnuts unshelled with different sizing and cracking systems. Journal of Agricultural Engineering Research, 67(3), 219-227. doi: 10.1006/jaer.1997.0163. 